\title{
SYNTHESIS AND CHARACTERIZATION OF THIOLATED JACKFRUIT SEED STARCH AS A COLONIC DRUG DELIVERY CARRIER
}

\author{
SANJOY DAS ${ }^{*}$, MALAY K. DAS ${ }^{1}$ \\ 1Department of Pharmaceutical Sciences, Dibrugarh University, Dibrugarh, Assam 786004, India \\ Email: sanjoyeyeconic@gmail.com
}

Received: 07 Jan 2019, Revised and Accepted: 05 Mar 2019

\begin{abstract}
Objective: Site-specific drug delivery into the colonic region is extremely fascinating for local treatment of various colonic diseases like ulcerative colitis, colon cancer but it should be capable of saving the drug from hydrolysis and degradation. The present study reports the application of jackfruit seed starch and its thiol derivative as a drug delivery carrier for the colon.

Methods: The starch was extracted from the jackfruit seeds by water extraction method and modified by the esterification reaction with thioglycolic acid. The thiolated starch was characterized for morphology, functional and flow properties. The safety profile of the thiolated starch was confirmed by acute toxicity study in a mice model as per OECD guidelines 423. The microspheres based on thiolated starch were prepared by ionic gelation method incorporating Ibuprofen as a model drug. The prepared microspheres were characterized for particle size, drug entrapment efficiency, drug loading, compatibility study, surface morphology, in vitro drug release and release kinetics.

Results: The result attributed that starch was successfully modified by the thiolation with a degree of substitution of 3.30 . The size of prepared microspheres ranges from $825.5 \pm 4.58$ to $857 \pm 6.24 \mu \mathrm{m}$, the entrapment efficiencies ranges from $69.23 \pm 1.19$ to $76.15 \pm 0.83 \%$ and the drug loading capacity ranges from $17.75 \pm 0.30$ to $46.05 \pm 0.49 \%$. The FT-IR, DSC and XRD studies confirmed that there is no interaction within drug and excipients. The thiolated starch microspheres show the maximum release of drug at $\mathrm{pH} 7.4$ in the presence of rat caecal content as compared to $\mathrm{pH}$ 1.2 and $\mathrm{pH} 6.8$ for up to $24 \mathrm{~h}$ and are following first order release kinetics.
\end{abstract}

Conclusion: These results suggest the application of thiolated jackfruit seed starch could be promising as a long-term drug delivery carrier for the colon.

Keywords: Starch, Jackfruit seed, Thiolation, Microspheres, Colon targeting

(C) 2019 The Authors. Published by Innovare Academic Sciences Pvt Ltd. This is an open-access article under the CC BY license (http://creativecommons.org/licenses/by/4.0/] DOI: http://dx.doi.org/10.22159/ijap.2019v11i3.31895

\section{INTRODUCTION}

Starch is the most frequently used excipients in pharmaceutical formulations based on its thickening, adhesive, gelling, swelling, filmforming properties, biodegradability, biocompatibility and non-toxicity $[1,2]$. Jackfruit (Artocarpus heterophyllus, belonging to the family Moraceae) is one of the well-known tropical fruits broadly grown-up in tropical countries and its seeds are tremendous sources of starch and protein $[3,4]$. Native starches are offensive for many applications due to their inefficiency to withstand various processing requirements such as high temperature, diverse $\mathrm{pH}$, so there is urgent to improve the desired functional properties via chemical modification [5]. Chemical modification is mainly attained through the addition of several functional groups into the starch molecules to encounter the different demand of applications [6, 7]. Thiomers serve as a new commitment in the field of polymers and provide numerous applications such as the improved controlled release of formulation, permeation and reduced irritation [8]. Thiomers are easily obtained by the incorporating thiol functional group $(-\mathrm{SH})$ to the polymeric backbone via substitution reaction resulting in thiolated polymer $[9,10]$.

Targeted delivery of drug molecules into the colonic region is highly fascinating for local treatment of various bowel diseases allied with the colon or large intestines like Crohn's disease, colonic cancer and ulcerative colitis [11]. Common methods for the targeted drug delivery to the colon are stationed on the chemical and technological modification of polymers [12]. Most of the polysaccharides are hydrophilic in nature, leading to the early release of the drug before arriving at the target sites [13]. For this reason, some of the polysaccharides like starch, pectin and guar gum have been chemically modified to upgrade their lipophilicity, resulting in effective treatment by targeted delivery of drug $[14,15]$. Polymers with a thiol backbone function differently, they are degraded after liable to the low redox potential in the colon or either in the presence of bacterial enzymes leading to drug release in the colonic site $[16,17]$.

The objective of the present study was the development of a novel colon-specific drug delivery carrier based on thiolated jackfruit seed starch. The thiolated starch microspheres were prepared by ionic gelation method incorporating Ibuprofen as a model drug and evaluated its colon targeting efficacy by in vitro methods.

\section{MATERIALS AND METHODS}

\section{Materials}

Thioglycolic acid, sulphuric acid, calcium chloride, chitosan and silver nitrate were purchased from Hi-Media Laboratories Pvt. Ltd., Mumbai, India. Ibuprofen was purchased from Knoll Pharma Pvt. Ltd., New Delhi, India. Methanol, potassium thiocyanate and ferrous ammonium sulphate were purchased from Research Lab Fine Chem. Industries, Mumbai, India. All the other reagents and chemicals used were of analytical grade.

\section{Plant material}

Jackfruit seeds were collected from my hometown Agartala, Tripura, India. The jackfruit was cut manually with a sharp blade and the seeds were processed from the yellowish bulb. The processed seeds were scrubbed with tap water to eliminate their impurities.

\section{Starch extraction}

The starch was extracted from jackfruit seeds by the simple water extraction method. Initially, the jackfruit seeds were cleaned and white aril part (seed coats) was peeled off manually to recover the seeds and directly subjected to starch extraction. The brown seed coats were lyepeeled with the help of a knife to remove the thin spermoderm that covers the white cotyledons and washed with running tap water. The washed seeds $(100 \mathrm{gm})$ were sliced by grater and make a slurry with a sufficient quantity of distilled water and stirred continuously along with slight heating. The slurry was then filtered using a stainless-steel sieve and keeps for 2-3 h allowing to precipitation. After that supernatant was eliminated and remaining sediment was scrubbed with distilled water for three times. The starch was obtained as a thick paste and dried-up in a hot air oven at $40{ }^{\circ} \mathrm{C}$ for $10-12 \mathrm{~h}$. The starch cake was triturated with a mortar and pestle and stocked in air close container at room temperature for further use $[18,19]$. 


\section{Starch modification}

The extracted jackfruit seed starch was chemically modified by thiolation process. Simply, a homogenous solution of starch (2\%) was prepared by dissolving it in a sufficient amount of distilled water under moderate stirring. A mixture of thioglycolic acid (5-10\%) and sulphuric acid (1\%) was added slowly in starch solution with varying reaction parameters. After completion of reaction excess amount of methanol was added and formed a white precipitate. The white precipitate was suitably collected and washed repetitively with methanol, then dried under oven at normal room temperature. A white powder of thiolated starch was obtained [20].

\section{Determination of \% thiol content and degree of substitution}

The \% thiol content on the thiolated starch was determined according to the following protocol. The determination based on the chemical affinity of silver by thiol groups. Simply, $50 \mathrm{mg}$ of dried thiolated starch was dissolved in $50 \mathrm{ml}$ of $0.01 \mathrm{M}$ silver nitrate $\left(\mathrm{AgNO}_{3}\right)$ solution. The flask was wrapped to avoid liability to light and stirred in an automated shaker for $3 \mathrm{~h}$ before the testing. The additional $\mathrm{AgNO}_{3}$ was titrated with $0.01 \mathrm{M}$ potassium thiocyanate (KSCN) using ferrous ammonium sulphate hexahydrate as an indicator. The endpoint was determined when an extra amount of thiocyanate anion formed a red coloured complex with an iron compound $[20,21]$.

$\%$ Thiol content was determined according to the following formula:

$$
\% \text { Thiol Content }=\frac{(V 1-V 2) \times M 1 \times 1.6987}{M 2 \times W} \times 100
$$

Where, $\mathrm{V} 1$ = Volume of potassium thiocyanate for blank, V2 = Volume of potassium thiocyanate for the sample, M1 = Molarity of potassium thiocyanate, M2 = Molarity of silver nitrate, $\mathrm{W}=$ Weight of Sample.

The degree of substitution (DS) is elucidated as the mean number of the site per glucose unit that possesses a substitute group. The DS was determined according to the following formula [22, 23]:

$$
\text { DS }=\frac{162 \times(\% \text { Thiol Content })}{7500-(75 \times \% \text { Thiol Content })}
$$

Where, $162=$ Molecular weight of glucose unit, $7500=$ Molecular weight of the thiol group attached with 100 anhydro-glucose unit, 75 $=$ Molecular weight of the thiol group.

\section{Physicochemical characterization of jackfruit seed starch and thiolated starch}

\section{$\%$ Yield}

The $\%$ yield of native jackfruit seed starch, as well as thiolated starch, was calculated from the initial weight of raw materials used for the extraction and the total amount of product obtained [24].

\section{Iodine test}

To check the identity of the extracted starch, iodine test was performed [25].

\section{Moisture content}

The moisture content of native and thiolated starch was determined by evaporated dish containing $5 \mathrm{~g}$ of starch samples were heated to $105^{\circ} \mathrm{C}$ in an oven until such time that weight becomes constant [26].

$$
\text { Moisture Content }(\%)=\frac{W i-W f}{W i} \times 100
$$

Where, $\mathrm{W}_{\mathrm{i}}=$ Initial Weight of the Sample and $\mathrm{W}_{\mathrm{f}}=$ Final Weight of the Sample.

\section{pH determination}

The $\mathrm{pH}$ of the native and thiolated starch was determined by $5 \mathrm{gm}$ of the starch sample was added to a beaker comprising $20 \mathrm{ml}$ of distilled water, the contents were stirred for $5 \mathrm{~min}$ and the $\mathrm{pH}$ was measured using calibrated $\mathrm{pH}$ meter [27].

\section{Water absorption or holding capacity}

In a typical procedure, $1 \mathrm{gm}$ of the starch sample was weighed into a centrifuge tube and $10 \mathrm{ml}$ of water was added and vortexed thoroughly. The suspensions were allowed to stand at room temperature for 1 hour and then centrifuged at $2000 \mathrm{rpm}$ for 10 min. The volume of water on the sediment was measured and the water absorption capacity was expressed as $\mathrm{ml}$ of water absorbed by the $1 \mathrm{~g}$ of $\operatorname{starch}(\mathrm{v} / \mathrm{w})$ [28].

\section{Swelling power and solubility}

The swelling power and solubility of native and thaiolated starch were determined according to the method described by Nadiha et al. (2010) with minor modification. Simply, $1 \mathrm{~g}$ of the starch sample was weighed and mixed with $10 \mathrm{ml}$ of water in a centrifuge tube and heated at $80^{\circ} \mathrm{C}$ for $30 \mathrm{~min}$. The mixture was continuously shaken during the heating period. After heating, the mixture was cooled at room temperature and centrifuged at 10,000 rpm for $15 \mathrm{~min}$. The supernatant was carefully removed and the sediment paste was weighed. The supernatant was evaporated overnight at $110{ }^{\circ} \mathrm{C}$. The swelling power and solubility were calculated according to the following formula [29]:

$$
\begin{aligned}
& \text { Swelling Power }(\mathrm{g} / \mathrm{g})=\frac{\text { Weight of the wet sediment }(\mathrm{g})}{\text { Weight of the dry starch }(\mathrm{g})} \\
& \text { Solubility }(\%)=\frac{\text { Weight of dried supernatant }(\mathrm{g})}{\text { Weight of the dry starch }(\mathrm{g})} \times 100
\end{aligned}
$$

\section{Gelation properties}

The gelation properties were determined as per the standard method with minor modification. Simply, the starch slurry of 1-10\% concentration were prepared in test tubes and mixed properly with the help of vortex shaker. The test tubes were heated at $85{ }^{\circ} \mathrm{C}$ in a water bath for $30 \mathrm{~min}$, followed by rapid cooling under the running tap water. The test tubes were further cooled at $4{ }^{\circ} \mathrm{C}$ for $2 \mathrm{~h}$. The lowest gelation concentration (LGC) was determined as that concentration when the sample from the inverted test tube did not fall down or slip [30].

\section{Angle of repose}

The fixed funnel method was used to determine the angle of repose of native and thiolated starch. The angle of repose was determined according to the following formula [31]:

$$
\theta=\tan ^{-1} \frac{h}{r}
$$

Where, $\theta=$ Angle of repose, $\mathrm{h}=$ Pile height, $\mathrm{r}=$ diameter of the circle.

\section{Bulk density and tapped density}

Simply, $5 \mathrm{gm}$ of the starch sample was weighed and transferred into a $100 \mathrm{ml}$ of measuring cylinder. The volume occupied by the sample recorded as bulk volume. The cylinder was dropped several times on wooden platform until the volume occupied by the starch remained constant. The volume occupied the sample recorded as tapped volume. The bulk density and tapped density were calculated by the following equation [32]:

$$
\begin{gathered}
\text { Bulk Density }=\frac{\text { Weight of the Sample }}{\text { Bulk Volume }} \\
\text { Tapped Density }=\frac{\text { Weight of the sample }}{\text { Tapped Volume }}
\end{gathered}
$$

\section{Hausner ratio and Carr's index}

The values obtained from bulk density and tapped density above were used to determine the Carr's Index and Hausner ratio according to the following formula [32]:

$$
\begin{gathered}
\text { Carr's Index }=\frac{\text { Tapped Density }- \text { Bulk Density }}{\text { Tapped Density }} \times 100 \\
\text { Hausner Ratio }=\frac{\text { Tapped Density }}{\text { Bulk Density }}
\end{gathered}
$$

\section{Morphological evaluation}

For morphological evaluation, optical microscopy and SEM analysis were performed [33]. 


\section{Acute toxicity study}

Acute toxicity study was conducted as per the Organization for Economic Cooperation and Development (OECD) Guidelines 423. The Institutional Animal Ethical Committee of Dibrugarh University, Dibrugarh, Assam, India approved the experimental protocol (Approval No. IAEC/DU/131 dated. 29/12/2016).

Healthy Swiss albino mice (female, 8 to $12 \mathrm{w}$ old) were chooses for the oral acute toxicity study. All the animals were haphazardly distributed into 5 groups, each comprising 3 mice and marked on the tail. The animals were housed properly in polypropylene mice cages for at least $7 \mathrm{~d}$ before dosing for acclimatizing the laboratory atmospheric conditions. The temperature in the animal house was preserved at $22 \pm 3{ }^{\circ} \mathrm{C}$ and the relative humidity was preserved at $70 \%$ and $12 \mathrm{~h}$ light/dark cycle was maintained quarantine. All the animals were consuming with regular laboratory diets with a complete supply of drinking water. The thiolated starch suspension was administered in a single dose by specially designed mice oral feeding needle. All the test animals were unfed overnight (only food was withheld but not water) before administering the test sample. The thiolated starch suspension was administered by the oral route at a dose of $5,50,300,2000 \mathrm{mg} / \mathrm{kg}$ body wt. After the administration of the test sample, food was concealed for additional $2 \mathrm{~h}$ and animals are observed separately once over the initial $30 \mathrm{~min}$, with special consideration given over the first 4 $\mathrm{h}$ and daily consequently for a total of $14 \mathrm{~d}$ [34].

\section{Preparation of microspheres using thiolated starch}

The microspheres were prepared by ionic gelation method using various concentration of thiolated starch as a cell forming polymer with varying concentration of $\mathrm{CaCl}_{2}$ as a cross-linking agent. The polymer solution was prepared by dissolving thiolated starch in $2 \mathrm{~N}$ $\mathrm{NaOH}$ solution with vigorous mixing on a magnetic stirrer and drug (Ibuprofen) was then added to the polymer solution. Cross-linking agent solution was prepared by dissolving $\mathrm{CaCl}_{2}$ (anhydrous) in distilled water. The polymer solution was then added manually dropwise into crosslinking agent solution through a syringe (Needle size 24 gauge) under continuous stirring at 100-200 rpm. The added droplets were kept dispersed in the $\mathrm{CaCl}_{2}$ solution for 25-30 min to finish the curing reaction and to develop spherical rigorous microspheres. The microspheres were carefully collected and Scrubbed with distilled water 2-3 times and dried in a hot air oven at $40{ }^{\circ} \mathrm{C}$ for $12-18 \mathrm{~h}$ [35]. Before preparing the drug-loaded microspheres, blank microspheres were prepared by taking a different concentration of polymer and the crosslinking agent.

\section{Characterization of microspheres}

\section{$\%$ Yield}

The $\%$ yield of microspheres was calculated by the total weight of microspheres obtained from the total weight of the drug and excipients used [36].

$$
\text { Yield (\%) }=\frac{\text { Total Weight of Microspheres }}{\text { Total Weight of the Drug and Excipients }} \times 100
$$

\section{Swelling behaviour}

The swelling behaviour of the blank microspheres was carried out in three different aqueous media i.e., $\mathrm{pH} 1.2, \mathrm{pH} 6.8$ and $\mathrm{pH} 7.4$ for $5 \mathrm{~h}$. $10 \mathrm{mg}$ of microspheres were placed in the beaker containing $50 \mathrm{ml}$ of respective media. The study was carried out at $37 \pm 1{ }^{\circ} \mathrm{C}$. The swelled beads were removed at a predetermined time interval and weighed after drying the surface by using tissue paper [37]. Swelling index was determined using the following formula: Swelling Index $(\%)=$
$\frac{\text { Weight of Microspheres After Swelling }- \text { Dry Weight of Microspheres }}{\text { Dry Weight of Microspheres }} \times 100$

\section{Drug entrapment and loading efficiency}

To find out the drug entrapment and loading efficiency, $10 \mathrm{mg}$ of dried microspheres were powdered and disbursed in $10 \mathrm{ml}$ of phosphate buffer $\mathrm{pH} 7.4 \mathrm{up}$ to $24 \mathrm{~h}$. After $24 \mathrm{~h}$, the solution was filtered by using a $0.45 \mu \mathrm{m}$ Whatman syringe filter and the concentration of the ibuprofen present in the filtrate was found out spectrophotometrically at $222 \mathrm{~nm}$ using UV-Visible Spectrophotometer (Shimadzu, UV-1800, Japan) with respect to phosphate buffer $\mathrm{pH} 7.4$ solution as a blank [38, 39].

$$
\begin{gathered}
\text { Drug Entrapment Efficiency (\%) }=\frac{\text { Practical Drug Content }}{\text { Theoretical Drug Content }} \times 100 \\
\text { Drug Loading (\%) }=\frac{\text { Practical Drug Content }}{\text { Total Weight of Microspheres Obtained }} \times 100
\end{gathered}
$$

\section{Drug-polymer compatibility study}

To determine any type of interaction between the drug and excipients, FT-IR, DSC and XRD analysis were done for the drug, polymer and drug-loaded microspheres.

In the FT-IR analysis, samples were simply placed over the sample holder of the FT-IR spectrometer (Bruker Alpha, Germany) and spectral scanning was taken in the wavelength region between $4000-400 \mathrm{~cm}^{-1}$. FT-IR spectrometer is a useful tool for detecting the types of chemical bonds, functional groups and also examines the integrity of drug in the formulation [40].

The DSC patterns of pure drug ibuprofen, physical mixture and ibuprofen-loaded microspheres were observed using Differential Scanning Colorimeter (DSC 4000, Perkin Elmer, U. S. A.). Around $5 \mathrm{mg}$ of the sample was pinched in a standard aluminum pan and heated across a temperature range of $40{ }^{\circ} \mathrm{C}$ to $400{ }^{\circ} \mathrm{C}$ with a constant linear heating rate of $10^{\circ} \mathrm{C}$ per minute. The DSC analysis generally used to examine the purity, thermal transitions, compatibility of drug and polymers [41].

The impact of microencapsulation mapping on drug crystallinity was studied using XRD analysis. XRD patterns of pure drug ibuprofen, physical mixture and ibuprofen-loaded microspheres were recorded by X-Ray Diffractometer (Rigaku-Ultima IV, Japan), using $\mathrm{Cu}$ radiation, a voltage of $40 \mathrm{kV}$ and a current of $30 \mathrm{~mA}$. The scanning speed employed was $2 \%$ min above the range of $10^{\circ}$ to $80^{\circ}$ diffraction angle [42].

\section{Morphological characterization}

The particle size of the starch sample, drug-loaded microspheres were determined by optical microscopy technique using a compound microscope (Olympus, India) equipped with ocular and stage micrometer. After the calibration, stage micrometer was removed and the diameter of starch sample and microspheres was determined using calibrated ocular micrometer [43].

In the SEM analysis, samples were spread onto a metal stub with twofold adhesive tape. The metal stubs were then covered with gold-palladium applying gold sputter coater in a high vacuum evaporator. The surface characteristics of the sample were obtained from the secondary electrons directed by the external surface of the sample. The coated samples were then randomly scanned and photographs were taken using a scanning electron microscope (ZEISS MultiSEM 505, Germany) [44].

\section{In vitro drug release study}

The in vitro drug release studies were performed by the USP Dissolution Test Apparatus Type 1 (Basket Type, LABINDIA DS 8000) in $900 \mathrm{ml}$ dissolution medium at $50 \mathrm{rpm}$ and the temperature of the medium was preserved at $37{ }^{\circ} \mathrm{C} \pm 0.5{ }^{\circ} \mathrm{C}$. An absolutely weighed amount of prepared microspheres (equivalent to $10 \mathrm{mg}$ of drug) were used for the study. The experiment was performed using simulated GI fluid (SGF) pH 1.2 for the first $2 \mathrm{~h}$. Then the medium was exchanged with phosphate buffer $\mathrm{pH} 6.8$ for the next $3 \mathrm{~h}$ and then the medium was again exchanged with phosphate buffer $\mathrm{pH} 7.4$ with rat caecal content up to $24 \mathrm{~h}$. At regular time intervals, $5 \mathrm{ml}$ of sample was withdrawn and replaced by $5 \mathrm{ml}$ of the fresh medium after each sampling to preserve the constant volume (sink condition) during the whole test. The sample was filtered using $0.45 \mu \mathrm{m}$ Whatman syringe filter and assayed spectrophotometrically at $222 \mathrm{~nm}$ using a UVVisible spectrophotometer (Shimadzu, UV-1800, Japan) [45]. Rat caecal content was processed according to the method described in elsewhere. Simply, 2 albino rats of identical body weight (150-200 gm) with no earlier drug treatment were taken. The animals were weighed and provided on a normal diet. $30 \mathrm{~min}$ before to starting the 
experiment, each rat was humanely sacrificed and opened the abdomen. The caecum was traced in rats, bind at both ends with a ligature, dissected and instantly transferred into a phosphate buffer solution pH 6.8. The caecal bags were carefully opened; contents were processed, properly blended and then disbursed in phosphate buffer $\mathrm{pH} 7.4$ to give the appropriate concentration of caecal content [46].

\section{In vitro drug release kinetics}

To examine the release mechanism of ibuprofen from the microspheres, the in vitro drug release data were fitted into various kinetic models like Zero order, First order, Higuchi model and Korsmeyer-Peppas (K-P) model. By comparing the obtained $\mathrm{R}^{2}$ values, the best-fit model was picked up [47].
The experimental values were processed using Microsoft Excel 2016 software (Analysis ToolPak) and results were expressed as mean \pm SD.

\section{RESULTS AND DISCUSSION}

\section{Extraction and modification of starch}

The jackfruit seed starch was extracted by the simple water extraction method and identified using the iodine test resulting to blue colouration in the presence of iodine solution. After the starch extraction, it has been chemically modified by thiolation. Thiolation of jackfruit seed starch was presented in fig. 1. In a typical thiolation process, the hydroxyl groups of the starch react with the carboxyl groups $(-\mathrm{COOH})$ of thioglycolic acid and form thiolated starch having sulfhydryl $(-\mathrm{SH})$ terminal groups in the matrix.

\section{Data analysis}

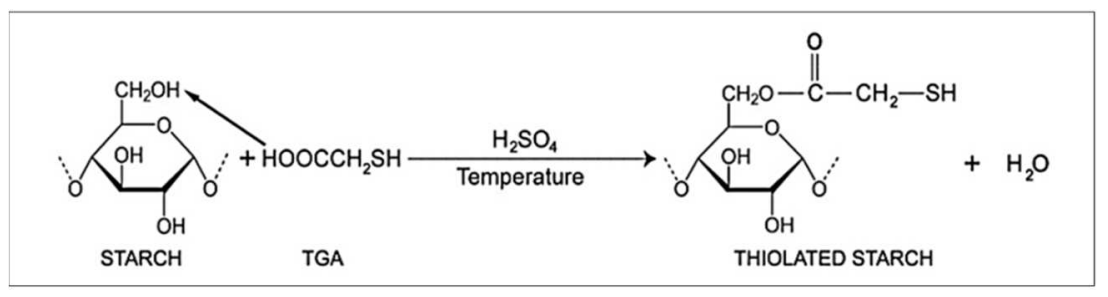

Fig. 1: Schematic representation of thiolation process

Various parameters like starch concentration, thioglycolic acid (TGA) concentration, reaction temperature and reaction time, the $\%$ thiol content and degree of substitution (DS) have been investigated and results were shown in table 1

Table 1: \% Thiol content and degree of substitution of thiolated jackfruit seed starch

\begin{tabular}{|c|c|c|c|c|c|c|c|}
\hline S. No. & Trial & Starch (\%) & TGA* (\%) & Reaction temperature $\left({ }^{\circ} \mathrm{C}\right)$ & Reaction time (H) & \% Thiol content & DS* \\
\hline 01. & Trial 1 & 2 & 10 & 60 & 3 & 60.46 & 3.30 \\
\hline 02. & Trial 2 & 2 & 5 & 60 & 3 & 45.86 & 1.82 \\
\hline 03. & Trial 3 & 2 & 10 & 50 & 3 & 40.42 & 1.46 \\
\hline 04. & Trial 4 & 2 & 5 & 50 & 3 & 26.48 & 0.77 \\
\hline
\end{tabular}

*TGA $=$ Thioglycolic Acid, DS = Degree of Substitution.

From the above observation, the starch concentration was selected at 2 $\%$ because above $2 \%$ starch become gel or paste during heating, so it may be difficult to the proper substitution of the thiol group to the starch moiety. TGA concentration was selected at $5 \%$ and $10 \%$ because the thiolation process was strongly dependent on the acid concentration. Therefore, a larger concentration of acid assisted the ester formation. The reaction couldn't be monitored beyond $10 \%$ of TGA concentration because of the high exothermic nature of the reaction. The reaction was assembled in the temperature range of 50 to $60{ }^{\circ} \mathrm{C}$ at various thiol content to investigate the esterification process. In the typical esterification process, time is generally required for 2 to $3 \mathrm{~h}$ for proper substitution Moreover, during the reaction, TGA has the characteristic smell (due to the presence of sulphur) and thereafter the smell gets distant indicating the completion of reaction $[20,48]$. The thiol content and substitution is extremely influenced by the concentration of thioglycolic acid and reaction temperature due to higher the temperature greater the conversion of thioglycolic acid. The rate of reaction was greatly depended on the function of temperature and the forward reaction was faster leading to more ester formation during the reaction $[49,50]$.

After the determination of thiol content and degree of substitution (DS), the best trial i.e., Trial 1 ( $\%$ thiol content $=60.46$ and degree of substitution $=3.30$ ) was picked up for the further characterization.

Physicochemical characterization of jackfruit seed starch and thiolated starch

The $\%$ yield of native jackfruit seed starch and thiolated starch are shown in table 2.

Table 2: \% Yield of jackfruit seed starch and thiolated starch

\begin{tabular}{llll}
\hline S. No. & Jackfruit seed starch & \multicolumn{2}{c}{ Thiolated starch } \\
\cline { 2 - 4 } & Batch & \% Yield & Batch \\
\hline 01. & Batch 1 & 32.8 & Batch 1 \\
02. & Batch 2 & 33.0 & Batch 2 \\
03. & Batch 3 & 32.3 & Batch 3 \\
04. & Batch 4 & 31.9 & Batch 4 \\
05. & Batch 5 & 32.5 & Batch 5 \\
\hline
\end{tabular}

The moisture content, $\mathrm{pH}$, water absorption capacity, swelling power, solubility, gelation properties and angle of repose, bulk density, tapped density, Carr's index, Hausner ratio, particle size of native jackfruit seed starch as well as thiolated starch was determined and results were shown in table 3 , table 4 and table 5 . 
Table 3: pH, moisture content, water absorption capacity, swelling power, solubility

\begin{tabular}{llll}
\hline S. No. & Parameters & Jackfruit seed starch & Thiolated starch \\
\hline 01. & $\mathrm{pH}$ & $6.1 \pm 0.1$ & $2.5 \pm 0.1$ \\
02. & Moisture Content (\%) & $8.6 \pm 0.2$ & $3.2 \pm 0.3$ \\
03. & Water Absorption Capacity (ml/g) & $1.63 \pm 0.05$ & $2.96 \pm 0.15$ \\
04. & Swelling Power (g/g) & $3.33 \pm 0.06$ & $1.69 \pm 0.06$ \\
05. & Solubility (\%) & $18.4 \pm 0.4$ & $13.2 \pm 0.4$ \\
\hline
\end{tabular}

Data are presented as mean $\pm \mathrm{SD}(\mathrm{n}=3)$.

The physicochemical characterization of native jackfruit seed starch was significantly changed after thiolation (table 3). The $\mathrm{pH}$ and moisture content of native jackfruit seed starch was found more than that of thiolated starch, due to the thiol group having the more affinity to accept electron pair and donating proton than oxygen. According to Lewis theory, a substance having more affinity for accepting an electron pair and donating proton is called acid and having the $\mathrm{pH}$ in the acidic range [51]. During thiolation, the hydroxyl group of the starch was replaced by the thiol group. As we know that hydroxyl having the higher affinity to absorb the moisture [52]. The water holding or absorption capacity was found more in case of thiolated starch, due to the introduction of thiol functional groups and their electrostatic repulsion facilitated the holding of water with the starch matrices [53]. The solubility and swelling power of native jackfruit seed starch was found more than that of thiolated starch, due to hydroxyl group of native starch form hydrogen bond with water molecules which favoring the more swelling and solubility but in case of thiolated starch, thiol group affected the intragranular force interactions which lowering the swelling and solubility [54].

The gelation properties of the native jackfruit seed starch were reduced after thiolation (table 4). The least gelation concentration (LGC) increased from $3 \%$ for native starch to $7 \%$ for thiolated starch. During thiolation some of the hydroxyl hydrogens of the starch molecule are exchanged by the thiol groups, thus interferes with the strength of hydrogen bonding with water molecule leading to the formation of weak gels in case of thiolated starch [55].

Table 4: Gelation properties of jackfruit seed starch and thiolated starch

\begin{tabular}{llll}
\hline S. No. & Concentration & Jackfruit seed starch & Thiolated starch \\
\hline 01. & 1 & Slightly Gelled & Not Gelled \\
02. & 2 & Slightly Gelled & Not Gelled \\
03. & 3 & Gelled & Selled \\
04. & 4 & Gelled & Slightly Gelled \\
05. & 5 & Gelled & Slightly Gelled \\
06. & 6 & Gelled & Gelled \\
07. & 7 & Gelled & Gelled \\
08. & 8 & Gelled & Gelled \\
09. & 9 & Gelled & Gelled \\
10. & 10 & Gelled & $7 \%$ \\
Least Gelation Concentration $(L G C)$ & $3 \%$ & \\
\hline
\end{tabular}

Table 5: Angle of repose, bulk density, tapped density, Carr's index, Hausner ratio, particle size

\begin{tabular}{llll}
\hline S. No. & Parameters & Jackfruit seed starch & Thiolated starch \\
\hline 01. & Angle of Repose $\left({ }^{\circ}\right)$ & $28.80 \pm 0.44$ & $25.63 \pm 0.93$ \\
02. & Bulk Density $(\mathrm{g} / \mathrm{ml})^{\text {Tapped Density }(\mathrm{g} / \mathrm{ml})}$ & $0.35 \pm 0.005$ & $0.34 \pm 0.005$ \\
03. & Carr's Index $(\%)$ & $0.41 \pm 0.005$ & $0.38 \pm 0.005$ \\
04. & Hausner Ratio & $14.51 \pm 0.20$ & $11.19 \pm 1.41$ \\
05. & Particle Size $(\mu \mathrm{m})$ & $1.16 \pm 0.01$ & $1.12 \pm 0.01$ \\
06. & & $43.80 \pm 0.36$ & $35.96 \pm 0.75$ \\
\hline
\end{tabular}

Data are presented as mean $\pm \operatorname{SD}(n=3)$.

The above results (table 5) revealed that the native jackfruit seed starch and thiolated starch have good flow properties according to USP monographs and there were no detectable changes in the size of the native starch particles following thiolation [56].

\section{Acute toxicity study}

Acute oral toxicity study of thiolated starch was performed in a mice model with a dose of 5, 50, 300 and $2000 \mathrm{mg} / \mathrm{kg}$ body wt. The $\mathrm{LD}_{50}$ of the thiolated starch was not calculated because the test substance did not produce any mortality up to the dose of 2000 $\mathrm{mg} / \mathrm{kg}$ body wt. No such dissimilarities were found in growth behavior (somatomotor activity, behavioral changes) and body weight of the animals between control and treated groups [57].
The body weights of the control and treated animals were shown in table 6 .

The toxicity study reveals that no acute adverse reactions like convulsions, salivation, lethargy, diarrhea in the albino mice during the entire observation period. Therefore, it was assumed that thiolated starch was easily digested by the animals by avoiding any kind of toxic effects [58].

\section{Characterization of microspheres}

The blank microspheres were characterized for particle size and swelling index to obtain the optimized formulation and results were shown in table 7.

Table 6: Body weight of control and treated animals

\begin{tabular}{llllll}
\hline S. No. & Day & Control & $\mathbf{5 ~} \mathbf{~ g} / \mathbf{k g}$ & $\mathbf{5 0} \mathbf{~ m g} / \mathbf{k g}$ & $\mathbf{3 0 0} \mathbf{~} \mathbf{g g} / \mathbf{k g}$ \\
\hline 01. & 1 & $27.33 \pm 4.50$ & $26 \pm 2$ & $28.33 \pm 0.57$ & $28.66 \pm 1.15$ \\
02. & 7 & $28 \pm 4$ & $26.66 \pm 1.52$ & $29 \pm 1$ & $29.33 \pm 1.52$ \\
03. & 14 & $29.33 \pm 3.51$ & $28 \pm 1.73$ & $30.33 \pm 0.57$ & $30.66 \pm 1.15$ \\
\hline
\end{tabular}

Data are presented as mean $\pm \mathrm{SD}(\mathrm{n}=3)$. 
Table 7: Characterization of blank microspheres

\begin{tabular}{|c|c|c|c|c|c|c|c|c|}
\hline \multirow[t]{2}{*}{ S. No. } & \multirow[t]{2}{*}{ Formulation } & \multirow[t]{2}{*}{ Thiolated starch (\% w/v) } & \multirow{2}{*}{$\begin{array}{l}\mathrm{CaCl}_{2} \\
(\% \mathrm{w} / \mathrm{v})\end{array}$} & \multirow[t]{2}{*}{$\%$ Yield } & \multicolumn{3}{|c|}{ Swelling index (\%) } & \multirow[t]{2}{*}{ Particle size $(\mu \mathrm{m})$} \\
\hline & & & & & pH 1.2 & pH 6.8 & pH 7.4 & \\
\hline 01. & BF-1 & 5 & 5 & 70.10 & $75 \pm 1$ & $167.6 \pm 1.5$ & $217.6 \pm 1.5$ & $818.3 \pm 1.54$ \\
\hline 02. & $\mathrm{BF}-2$ & 10 & 5 & 73.46 & $80.6 \pm 0.5$ & $177.3 \pm 0.5$ & $226 \pm 1$ & $979.3 \pm 2.08$ \\
\hline 03. & $\mathrm{BF}-3$ & 10 & 10 & 75.65 & $81.3 \pm 0.5$ & $171.6 \pm 1.5$ & $221.6 \pm 0.5$ & $932.0 \pm 1.73$ \\
\hline 04. & BF-4 & 5 & 10 & 71.93 & $76.6 \pm 1.5$ & $163 \pm 1$ & $212.3 \pm 1.5$ & $824.3 \pm 1.52$ \\
\hline
\end{tabular}

Data are presented as mean $\pm \mathrm{SD}(\mathrm{n}=3)$.

The above-specified results reported that swelling index of microspheres was found lower at $\mathrm{pH} 1.2$ as compared with that of $\mathrm{pH} 6.8$ and $\mathrm{pH}$ 7.4. This was mainly occurred due to the shrinking of thiolated starch at acidic $\mathrm{pH}$ [59]. Apart from the swelling index, particle size has greatly affected by the concentration of the crosslinking agent. For instances, increasing the concentration of $\mathrm{CaCl}_{2}$ particle size was significantly decreased, due to the shrinking of the particles might have arrived during the cross-linking process [60]. After the characterization of blank microspheres, the Formulation BF-4 was picked up for optimized formulation and the drug was loaded with that. The \% yield, drug entrapment efficiency, drug loading and particle size of ibuprofen-loaded thiolated starch microspheres and ibuprofen-loaded chitosan microspheres was determined and results were shown in table 8.

Table 8: Characterization of drug-loaded microspheres

\begin{tabular}{|c|c|c|c|c|c|c|c|c|}
\hline S. No. & Formulation & Drug (\% w/v) & $\begin{array}{l}\text { Polymer } \\
(\% \mathrm{w} / \mathrm{v})\end{array}$ & $\mathrm{CaCl}_{2}(\% \mathrm{w} / \mathrm{v})$ & $\%$ Yield & Particle size $(\mu \mathrm{m})$ & DEE* (\%) & $\mathrm{DL}^{*}(\%)$ \\
\hline 01. & F-1 & 1.25 & $\mathrm{TS}^{*}=5$ & 10 & 78.01 & $825.5 \pm 4.58$ & $69.23 \pm 1.19$ & $17.75 \pm 0.30$ \\
\hline 02. & $\mathrm{~F}-2$ & 2.5 & $\mathrm{TS}^{*}=5$ & 10 & 80.85 & $832.8 \pm 4.08$ & $73.73 \pm 0.97$ & $30.39 \pm 0.39$ \\
\hline 03. & F-3 & 3.75 & $\mathrm{TS}^{*}=5$ & 10 & 79.97 & $845.5 \pm 3.77$ & $74.01 \pm 1.02$ & $39.65 \pm 0.55$ \\
\hline 04. & F-4 & 5.0 & $\mathrm{TS}^{*}=5$ & 10 & 82.66 & $857 \pm 6.24$ & $76.15 \pm 0.83$ & $46.05 \pm 0.49$ \\
\hline 05. & CHTM* & 5.0 & $\mathrm{CHT}^{*}=5$ & $\mathrm{TPP}^{*}=10$ & 80.74 & $842.66 \pm 3.40$ & $70.67 \pm 0.81$ & $43.75 \pm 0.50$ \\
\hline
\end{tabular}

*TS=Thiolated Starch, CHT=Chitosan, TPP=Tripolyphosphate, CHTM=Chitosan Microspheres, DEE=Drug Entrapment Efficiency, DL=Drug Loading. Data are presented as mean $\pm \mathrm{SD}(\mathrm{n}=3)$.

The formulations of ibuprofen loaded-thiolated starch microspheres were successfully prepared by ionic gelation method. The formulation was optimized by changing the drug and polymer ratio and it has been seen that the microspheres size was increased as the amount of drug was increased and the polymer amount was decreased, a gummier internal phase occurred. During the crosslinking process, the internal phase was slowly dispersed because the cross-linking agent has more affinity over the aqueous phase which reduces the interfacial forces leading to the generation of larger microspheres $[61,62]$. The drug entrapment and loading efficiency were decreased, as the increased of polymer amount; this is due the fact that higher amount of polymer would produce smaller size droplets with higher surface area, so that diffusion of drug will be very fast resulting in the destruction of drug with a subsequent lowering of drug entrapment and loading efficiency [63]. After the evaluation of $\%$ yield, particle size, drug entrapment and loading efficiency of ibuprofen-loaded thiolated starch microspheres, the Formulation F-4 was selected as an optimized formulation for further characterization. For the comparison purpose, one batch ibuprofenloaded chitosan microspheres were prepared with the same concentration of the drug, polymer and crosslinking agent according to the Formulation F-4 (table 8) and further characterized [64].

\section{Drug-polymer compatibility study}

The FT-IR spectrum (fig. 2) of the pure drug ibuprofen, physical mixture and ibuprofen-loaded microspheres were obtained. From the FT-IR spectrum, it was observed that common peaks are present in both the spectra of native jackfruit seed starch and thiolated starch, but one extra peak i.e., S-H stretching (thiol group) at $2605.12 \mathrm{~cm}-1$ appeared in the spectrum of modified starch which confirms that starch was successfully modified by the thiolation [65]. Ibuprofen showed typical absorption bands at $1703.18 \mathrm{~cm}-1$ due to $\mathrm{C}=0$ stretching (acid group), at 745.93 , $775.08 \mathrm{~cm}-1$ due to $\mathrm{C}-\mathrm{H}$ stretching (aromatic) and at 2917.75, 2949.32 $\mathrm{cm}-1$ due to C-C stretching (alkane) vibrations. The FT-IR spectrum of physical mixture (Ibuprofen: Thiolated starch) and drug-loaded microspheres exhibited all the characteristics of absorption bands as that of drug ibuprofen without any notable variations [66]. The FT-IR spectra revealed that the drug has not gone through any kind of interactions with the excipients used and reserved its identity both in its physical mixture and formulation; indicate the no such interaction between the drug and excipients [67].

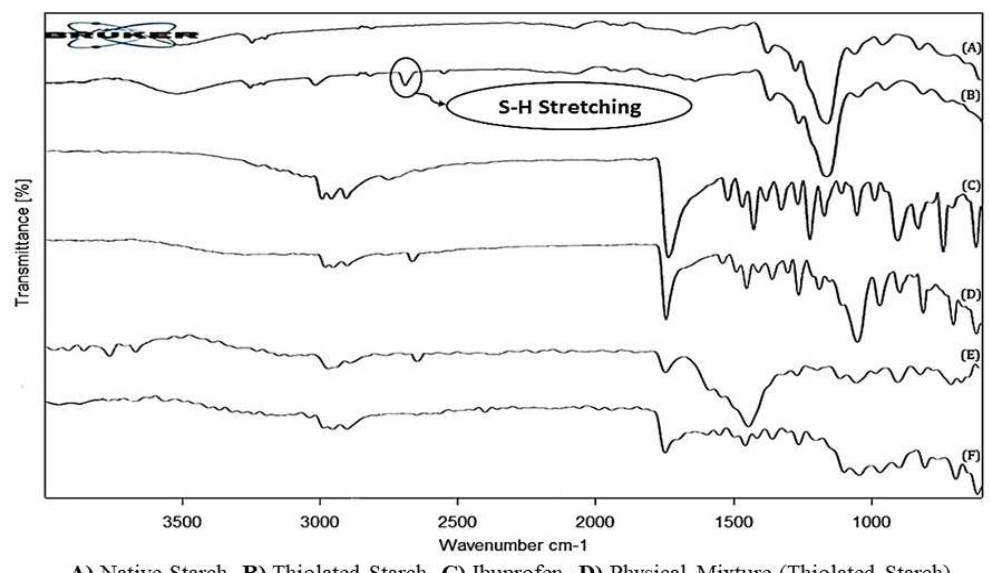

A) Native Starch, B) Thiolated Starch, C) Ibuprofen, D) Physical Mixture (Thiolated Starch), E) Ibuprofen-Loaded Thiolated Starch Microspheres, F) Ibuprofen-Loaded Chitosan Microspheres

Fig. 2: FT-IR spectrums 
The DSC thermogram (fig. 3) of the pure drug ibuprofen showed an endothermic peak which exhibiting its sharp melting point at $78.74{ }^{\circ} \mathrm{C}$. The thermogram of the physical mixture (Ibuprofen : Thiolated starch) revealed that the appearance of the ibuprofen endothermic peak at $77.68{ }^{\circ} \mathrm{C}$ resulting to the not being present any type of interaction within the drug and excipients. The thermogram of the ibuprofenloaded microspheres exhibited that the disappearance of the typical endothermic peak of ibuprofen, due to the drug was molecularly distributed in the polymeric core of the microspheres or existed in an amorphous nature $[68,69]$.

The X-Ray diffractogram (fig. 4) of the pure drug ibuprofen showed a group of sharp peaks which is reflective of its crystalline nature. The typical crystalline peaks of the drug are clearly visible in the physical mixture (Ibuprofen: Thiolated starch) without any significant differences in the positions and relative intensities, thereby ruling out any type of interaction within the drug and excipients. However, the diffractogram of the ibuprofen-loaded microspheres showed peaks of diminished intensities indicating that the drug was molecularly disbursed in the polymeric matrix or might have undergone amorphization during the microspheres preparation $[70,71]$. Compatibility studies confirmed that thiolated starch was compatible with drug and other excipients and doesn't get altered during formulation development.

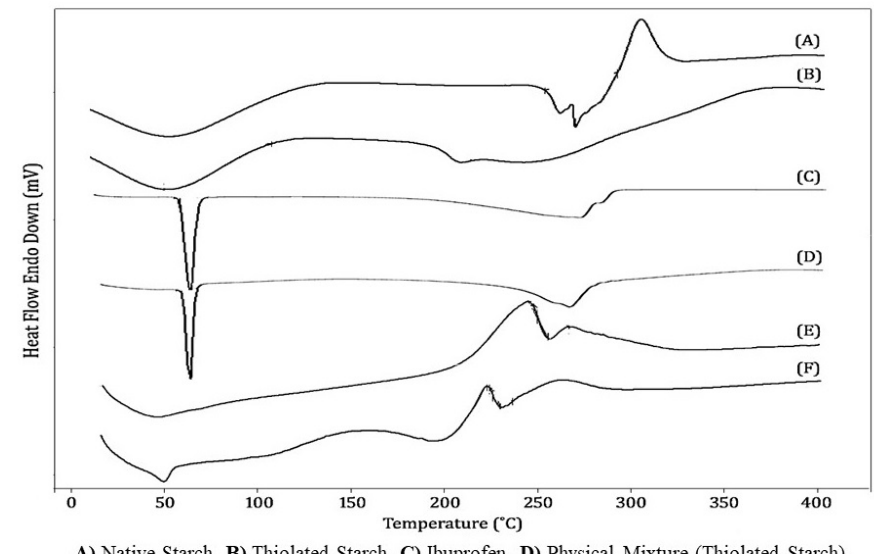

A) Native Starch, B) Thiolated Starch, C) Ibuprofen, D) Physical Mixture (Thiolated Starch), E) Ibuprofen-Loaded Thiolated Starch Microspheres, F) Ibuprofen-Loaded Chitosan Microspheres

Fig. 3: DSC thermograms

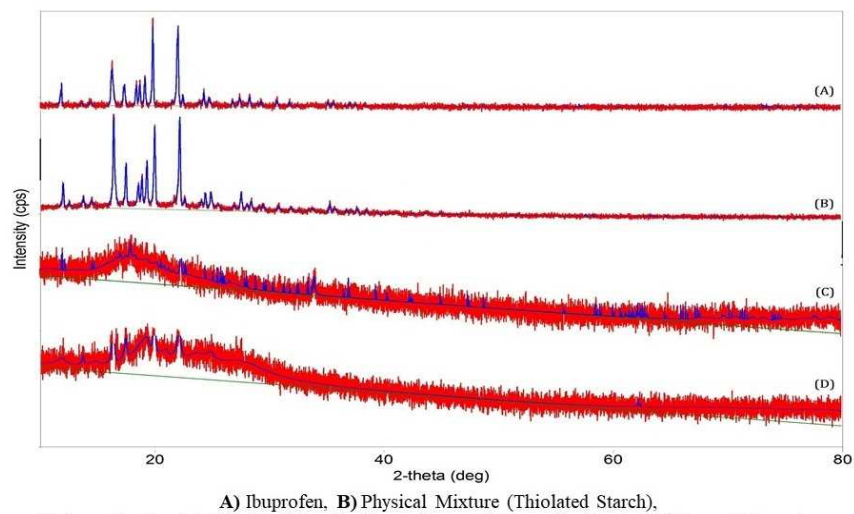

C) Ibuprofen-Loaded Thiolated Starch Microspheres, D) Ibuprofen-Loaded Chitosan Microspheres

Fig. 4: X-ray diffractograms

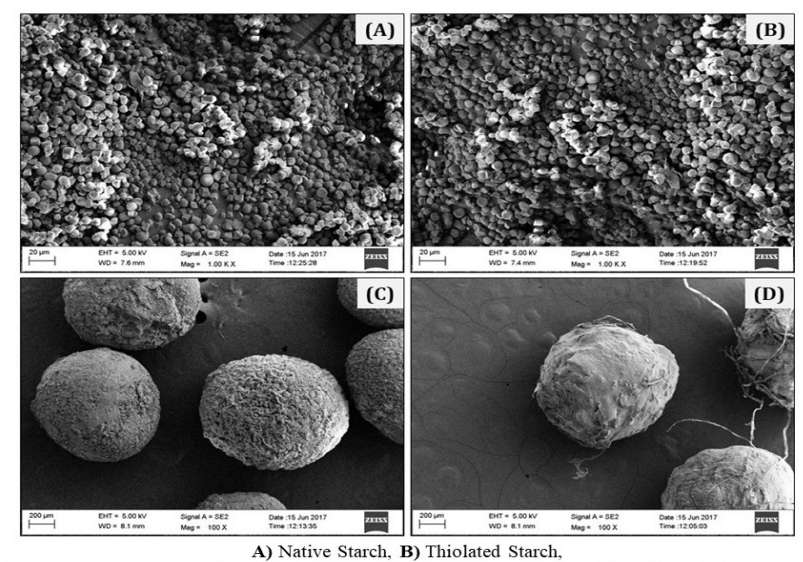

C) Ibuprofen-Loaded Thiolated Starch Microspheres, D) Ibuprofen-Loaded Chitosan Microspheres

Fig. 5: SEM photographs 


\section{Morphological characterization}

The shape and surface characteristics of starch samples and ibuprofen-loaded microspheres were assessed by scanning electron microscope (SEM). The SEM photographs were shown in fig. 5.

The SEM photographs affirmed that shape of starch granules were spherical and slightly polyhedral and the prepared microspheres were discrete, broadly spherical with rough surface characteristics and no such notable changes in the external surface of starch granules following thiolation and the surface of the microspheres was dense without any porous and some degree of roughness was observed in drug-loaded microspheres indicative of effective cross-linking [72].

\section{In vitro drug release study}

The release profile of Ibuprofen from the prepared microspheres was presented in fig. 6 .

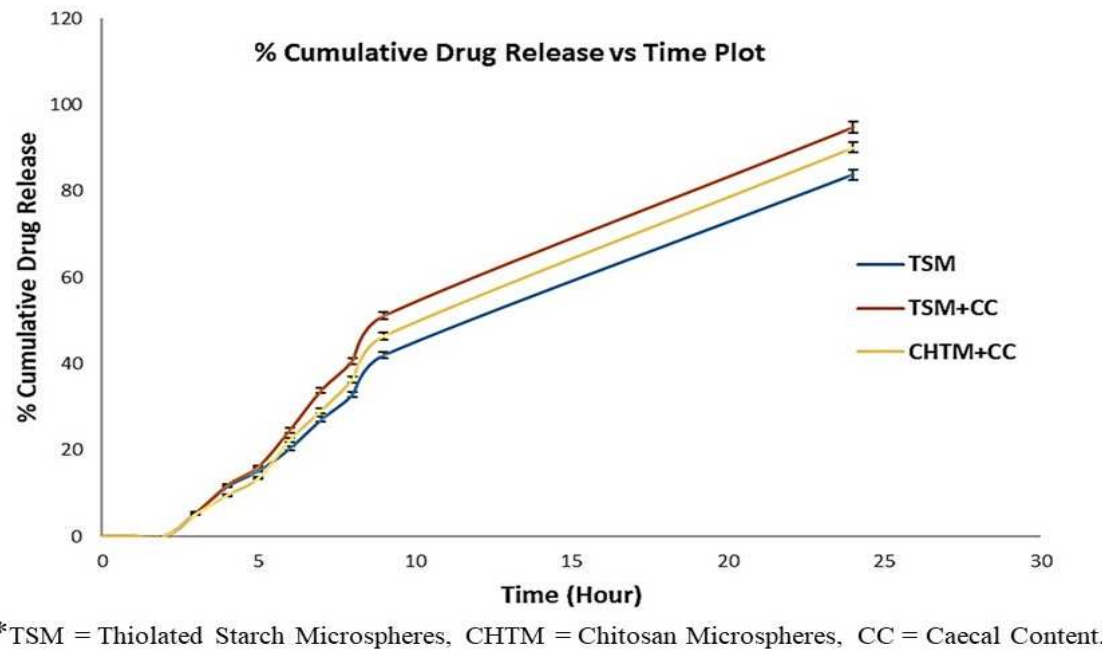

Fig. 6: Drug release profile of prepared microspheres. Each data points represented mean $\pm S D(n=3)$

The in vitro drug release study demonstrated that ibuprofen-loaded thiolated starch microspheres showed maximum drug release $(94.81 \pm 1.30 \%)$ in the existence of rat caecal content as compared to the ibuprofen-loaded chitosan microspheres in the same condition $(90.09 \pm 1.18 \%)$ and ibuprofen-loaded thiolated starch microspheres without caecal content $(83.77 \pm 1.10 \%)$ up to $24 \mathrm{~h}$. The release profiles revealed that drug release was significantly increased in the presence of caecal fluid due to the potentiality of nosocomial microflora present in the caecal content. These microorganisms might have released some enzymes which break down the thiolated starch particles of the microspheres leading to release of the encapsulated drug. In other ways, a substantial amount of glutathione present in the entire colonic region and colonic environment have low redox potential is the key feature of the drug release mechanism. Thiol (-SH) group is a powerful reducing agent and a strong nucleophile able to react with cellular toxicants or via the catalysis of the glutathione. Therefore, a polymer containing a thiol backbone could be easily deteriorated in the low redox potential environment of the human colon, leading to higher drug release [73-75].

\section{In vitro drug release kinetics}

The drug release mechanism was investigated by comparing the correlational coefficient $\left(\mathrm{R}^{2}\right)$ of the various kinetic models with one another by model fitting equation (table 9).

Table 9: Correlational coefficient $\left(R^{2}\right)$ of different kinetic models

\begin{tabular}{lllll}
\hline Formulation & Zero order kinetics & First order kinetics & Higuchi model & Korsmeyer-peppas model \\
\hline Thiolated Starch Microspheres + & $\mathbf{R}^{2}$ & $\mathbf{R}^{2}$ & $\mathbf{R}^{2}$ & $\mathbf{R}^{2}$ \\
Rat Caecal Content (TSM+CC) & 0.9451 & 0.9502 & 0.8716 & 0.9241 \\
\hline
\end{tabular}

After the comparison of $\mathrm{R}^{2}$ values, it has been seen that first order release model was found to be best fitted for drug release from the thiolated starch microspheres and release pattern was controlled by diffusion mechanism of the drug through the porous microspheres matrix. Since the matrix was comprised of polymer and drug molecules, the swelling effect was observed as a reliable volume dilation of the polymeric material, inducing the opening of pores around the matrix structure [76].

\section{CONCLUSION}

In this study, substitution of thiol group on jackfruit seed starch was achieved by esterification reaction with thioglycolic acid in the presence of sulfuric acid. Characterization of jackfruit seed starch and thiolated starch revealed that physicochemical properties were improved after thiolation and further thiolated starch was employed for the preparation of microparticulate drug carrier system. The microspheres based on thiolated starch were prepared by ionic gelation method incorporating model drug Ibuprofen. The result of swelling study attributed that thiolated starch microspheres swelled slowly in the acidic environment of the stomach (pH 1.2) in comparison to the target site i.e., colonic region $(\mathrm{pH}$ 7.4). While in vitro drug release study suggests that ibuprofen-loaded thiolated starch microspheres show the maximum release of drug at $\mathrm{pH} 7.4$ in the presence of rat caecal content than that of $\mathrm{pH} 1.2$ and pH 6.8 for up to $24 \mathrm{~h}$. Thus, thiolated starch was found to be suitable candidate for colonic drug delivery and may reducing the side effects of drugs caused by its absorption from the upper GIT when given in conventional or ordinary dosage form.

\section{ACKNOWLEDGMENT}

Authors are thankful to Drug Delivery Research Laboratory (DDRL), Department of Pharmaceutical Sciences, Dibrugarh University, Dibrugarh, Assam, India for providing the platform and equipment facilities to conduct the research work.

\section{COMPLIANCE WITH ETHICAL STANDARDS}

The Institutional Animal Ethical Committee of Dibrugarh University, Dibrugarh, Assam, India approved the experimental protocol (Approval No. IAEC/DU/131 dated. 29/12/2016). 


\section{AUTHORS CONTRIBUTIONS}

All the author have contributed equally

\section{CONFLICT OF INTERESTS}

The authors declare that they have no conflict of interest

\section{REFERENCES}

1. Manek RV, Builders PF, Kolling WM, Emeje M, Kunle OO. Physicochemical and binder properties of starch obtained from Cyperus esculentus. AAPS PharmSciTech 2012;13:379-88.

2. Henrist D, Bortel LV, Lefebvre R, Remon J. In vitro and in vivo evaluation of starch-based hot stage extruded double matrix systems. J Controlled Release 2001;75:391-400.

3. Rengsutthi K, Charoenrein S. Physico-chemical properties of jackfruit seed starch (Artocarpus heterophyllus) and its application as a thickener and stabilizer in chilli sauce. LWTFood Sci Technol 2011;44:1309-13.

4. Hettiaratchi UPK, Ekanayake S, Welihinda J. Nutritional assessment of a jackfruit (Artocarpus heterophyllus) meal. Ceylon Med J 2011;56:54-8.

5. Olayinka FS, Olayinka OO, Olu-Owolabi BI, Adebowale KO. Effect of chemical modifications on thermal, rheological and morphological properties of yellow sorghum starch. J Food Sci Technol 2015;52:8364-70.

6. Chen Q, Haojie Y, Wang L, Abdin ZU, Chen Y, Wang J, et al. Recent progress in chemical modification of starch and its applications. RSC Adv 2015;5:67459-74.

7. BeMiller JN, Huber KC. Physical modification of food starch functionalities. Annu Rev Food Sci Technol 2015;6:19-69.

8. Albrecht K, Bernkop Schnürch A. Thiomers: forms, functions and applications to nanomedicine. Nanomedicine 2007;2:41-50.

9. Bernkop Schnurch A. Thiomers: a new generation of mucoadhesive polymers. J Adv Drug Delivery Rev 2005;57:1569-82.

10. Bonengel $\mathrm{S}$, Bernkop Schnürch A. Thiomers-from bench to market. J Controlled Release 2014;194:120-9.

11. Philip AK, Philip B. Colon targeted drug delivery system: a review on primary and novel approaches. Oman Med J 2010;25:70-8.

12. Vandamme TF, Lenourry A, Charrueau C, Chaumeil JC. The use of polysaccharides to target drugs to the colon. Carbohydr Polym 2002;48:219-31.

13. Zhang N, Wardwell PR, Bader RA. Polysaccharide-based micelles for drug delivery. Pharmaceutics 2013;5:329-52.

14. Sinha VR, Kumria R. Polysaccharides in colon-specific drug delivery. Int J Pharm 2001;224:19-38.

15. Mundargi RC, Patil SA, Agnihotri SA, Aminabhavi TM. Development of polysaccharide-based colon targeted drug delivery systems for the treatment of amoebiasis. J Drug Dev Ind Pharm 2007;33:255-64.

16. Gyarmati B, Nemethy A, Szilagyi A. Reversible disulphide formation in polymer networks: a versatile functional group from synthesis to applications. Eur Polym J 2013;49:1268-86.

17. Zhang L, Sang Y, Feng J, Li Z, Zhao A. Polysaccharide-based micro/nanocarriers for oral colon-targeted drug delivery. J Drug Target 2016;24:579-89.

18. Chen J, Liang Y, Li X, Chen L, Xie F. Supramolecular structure of jackfruit seed starch and its relationship with digestibility and physicochemical properties. Carbohydr Polym 2016;150:269-77.

19. Singh J, Singh N. Studies on the morphological, thermal and rheological properties of starch separated from some indian potato cultivars. Food Chem 2001;75:67-77.

20. Gupta B, Anjum S, Ikram S. Preparation of thiolated polyvinyl alcohol hydrogels. J Appl Polym Sci 2013;129:815-21.

21. Hanif M, Zaman M, Qureshi S. Thiomers: a blessing to evaluating era of pharmaceuticals. Int J Polym Sci 2015;1:1-9.

22. Kumoro AC, Amalia R, Budiyati CR, Retnowati DS, Ratnawati R. Preparation and characterization of physicochemical properties of glacial acetic acid modified gadung (Diocorea hispida dennst) flours. J Food Sci Technol 2015;52:6615-22.

23. Bartz J, Goebel JT, Giovanaz MA, Zavareze EDR, Schirmer MA, Dias ARG. Acetylation of barnyardgrass starch with acetic anhydride under iodine catalysis. Food Chem 2015;178:236-42.
24. Pascoal AM, Di-Medeiros MCB, Batista KA, Leles MIG, Liao LM, Fernandes KF. Extraction and chemical characterization of starch from S. lycocarpum fruits. Carbohydr Polym 2013;98:1304-10.

25. Puri AV, Puranik VK, Kamble MD, Tauro SJ. Formulation and evaluation of diclofenac sodium tablet using isolated starch from unripe papaya fruits as the disintegrant. Indo Am J Pharm Res 2013;3:9183-9.

26. Madruga MS, Albuquerque FSM, Silva IRA, Amaral DS, Magnani M, Neto VQ. Chemical, morphological and functional properties of brazilian jackfruit (Artocarpus heterophyllus L.) seeds starch. Food Chem 2014;143:440-5.

27. Falade KO, Okafor CA. Physical, functional, and pasting properties of flours from corms of two cocoyam (Colocasia esculenta and Xanthosoma sagittifolium) cultivars. J Food Sci Technol 2015;52:3440-8.

28. Kaur M, Oberoi DPS, Sogi DS, Gill BS. Physicochemical, morphological and pasting properties of acid treated starches from different botanical sources. J Food Sci Technol 2011;48:460-5.

29. Nadiha MZN, Fazilah A, Bhat R, Karim AA. Comparative susceptibilities of sago, potato and corn starches to alkali treatment. Food Chem 2010;121:1053-9.

30. Chinma CE, Ariahu CC, Abu JO. Chemical composition, functional and pasting properties of cassava starch and soy protein concentrate blends. J Food Sci Technol 2013;50:1179-85.

31. Shah RB, Tawakkul MA, Khan MA. Comparative evaluation of flow for pharmaceutical powders and granules. AAPS PharmSciTech 2008;9:250-8.

32. Remya KS, Beena P, Bijesh PV, Sheeba A. Formulation development, evaluation and comparative study of effects of super disintegrants in cefixime oral disintegrating tablets. J Young Pharm 2010;2:234-9.

33. Zeng J, Gao H, Li G. Functional properties of wheat starch with different particle size distribution. J Sci Food Agric 2014;94:57-62.

34. OECD Guideline 423 for Testing of Chemicals. Acute oral toxicity-acute toxic class method; 2001.

35. Hari BNV, Praneetha T, Prathyusha T, Mounika K, Devi DR. Development of starch-gelatin complex microspheres as sustained release delivery system. J Adv Pharm Technol Res 2012;3:182-7.

36. Phutane P, Shidhaye S, Lotlikar V, Ghule A, Sutar S, Kadam V. In vitro evaluation of novel sustained release microspheres of glipizide prepared by the emulsion solvent diffusionevaporation method. J Young Pharm 2010;2:35-41.

37. Nayak AK, Pal D. Development of $\mathrm{pH}$-sensitive tamarind seed polysaccharide-alginate composite beads for controlled diclofenac sodium delivery using response surface methodology. Int J Biol Macromol 2011;49:784-93.

38. Patel JK, Patel RP, Amin AF, Patel MM. Formulation and evaluation of mucoadhesive glipizide microspheres. AAPS PharmSciTech 2005;6:49-55.

39. Thompson CJ, Hansford D, Higgins S, Rostron C, Hutcheon GA, Munday DL. Evaluation of ibuprofen-loaded microspheres prepared from novel copolyesters. Int J Pharm 2007;329:53-61.

40. Palanisamy M, Khanam J. Cellulose-based matrix microspheres of prednisolone inclusion complex: preparation and characterization. AAPS PharmSciTech 2011;12:388-400.

41. Gangurde HH, Chavan NV, Mundada AS, Derle DV, Tamizharasi S. Biodegradable chitosan-based ambroxol hydrochloride microspheres: effect of cross-linking agents. J Young Pharm 2011;3:9-14.

42. Masaelia R, Kashia TSJ, Dinarvand R, Tahriria M, Rakhshand V, Esfandyari-Manesh M. Preparation, characterization and evaluation of drug release properties of simvastatin-loaded PLGA microspheres. Iran J Pharm Res 2016;15:205-11.

43. Sinko PJ, Singh Y. Martin's physical pharmacy and pharmaceutical sciences. $6^{\text {th }}$ ed. New York: Lippincott Williams and Wilkins; 2011.

44. Yandrapu S, Kompella UB. Development of sustained-release microspheres for the delivery of SAR 1118, an LFA-1 antagonist intended for the treatment of vascular complications of the eye. J Ocul Pharmacol Ther 2013;29:236-48.

45. Nayak AK, Pal D. Blends of jackfruit seed starch-pectin in the development of mucoadhesive beads containing metformin HCl. Int J Biol Macromol 2013;62:137-45. 
46. Ramasamy T, Khandasamy US, Shanmugamb S, Ruttalad H. Formulation and evaluation of chondroitin sulphate tablets of aceclofenac for colon targeted drug delivery. Iran J Pharm Res 2012;11:465-79.

47. Dash S, Murthy PN, Nath LK, Chowdhury P. Kinetic modeling on drug release from controlled drug delivery systems. Acta Pol Pharm 2010;67:217-23.

48. Raymond CR, Paul JS, Marian EQ. Handbook of pharmaceutical excipients. $6^{\text {th }}$ ed. London: Pharmaceutical Press; 2009.

49. Wasewar K, Patidar S, Agarwal VK. Esterification of lactic acid with ethanol in a pervaporation reactor: modeling and performance study. Desalination 2009;243:305-13.

50. Schou Pedersen AM, Hansen SH, Moesgaard B, Østergaard J. Kinetics of the esterification of active pharmaceutical ingredients containing carboxylic acid functionality in polyethylene glycol: formulation implications. J Pharm Sci 2014;103:2424-33.

51. Vollhardt P, Schore N. Organic chemistry structure and function. $6^{\text {th }}$ ed. New York: W. H. Freeman and Company; 2011.

52. Gilbert HF. Thiol/disulfide exchange equilibria and disulfide bond stability. Methods Enzymol 1995;251:8-28.

53. Sahnoun M, Ismail N, Kammoun R. Enzymatically hydrolysed, acetylated and dually modified corn starch: physico-chemical, rheological and nutritional properties and effects on cake quality. J Food Sci Technol 2016;53:481-90.

54. Kumar KJ, Varma AKC, Panpalia SG. Physicochemical and release characteristics of acetylated Indian palmyrah retrograded shoot starch. Int J Biol Macromol 2014;69:108-13.

55. Osundahunsi OF, Seidu KT, Mueller R. Effect of presence of sulphurdioxide on acetylation and sorption isotherm of acetylated starches from cultivars of cassava. Food Chem 2014;151:168-74

56. United State Pharmacopeia USP 29-NF 24. U. S: United States Pharmacopeial Convention; 2008-2010.

57. Jothy SL, Zakaria Z, Chen Y, Lau YL, Latha LY, Sasidharan S. Acute oral toxicity of methanolic seed extract of Cassia fistula in mice. Molecules 2011;16:5268-82.

58. Jesus DR, Barbosa LN, Prando TBL, Martins LF, Gasparotto F, Guedes KMR, et al. Ninety-day oral toxicity assessment of an alternative biopolymer for controlled release drug delivery systems obtained from cassava starch acetate. Evid Based Complement Alternat Med 2015;390416:1-7.

59. Nayak AK, Pal D, Santra K. Development of calcium pectinatetamarind seed polysaccharide mucoadhesive beads containing metformin HCl. Carbohydr Polym 2014;101:220-30.

60. Mallappa MK, Kesarla R, Banakar S. Calcium alginate-neusilin US2 nanocomposite microbeads for oral sustained drug delivery of poor water-soluble drug aceclofenac sodium. J Drug Delivery 2015;826981:1-14.

61. Kim C, Kim M, Oh K. Preparation and evaluation of sustained release microspheres of terbutaline sulfate. Int J Pharm 1994;106:213-9.
62. Kumbar SG, Kulkarni AR, Aminabhavi M. Crosslinked chitosan microspheres for encapsulation of diclofenac sodium: effect of crosslinking agent. J Microencapsul 2002;19:173-80.

63. Mundargi RC, Shelke NB, Rokhade AP, Patil SA, Aminabhavi TM. Formulation and in vitro evaluation of novel starch-based tableted microsphere for controlled release of ampicillin. Carbohydr Polym 2008;71:42-53.

64. Dhawan S, Singla AK, Sinha VR. Evaluation of mucoadhesive properties of chitosan microspheres prepared by different methods. AAPS PharmSciTech 2004;5:1-7.

65. Zhu X, Su M, Tang S, Wang L, Liang X, Meng F, et al. Synthesis of thiolated chitosan and preparation nanoparticles with sodium alginate for ocular drug delivery. Molecular Vis 2012;18:197382.

66. Khaskheli AR, Sirajuddin, Sherazi STH, Mahesar SA, Kandhro $\mathrm{AA}$, Kalwar $\mathrm{NH}$, et al. Estimation of ibuprofen in urine and tablet formulations by transmission fourier transform infrared spectroscopy by partial least square. Spectrochim Acta A Mol Biomol Spectrosc 2013;102:403-7.

67. Bulut E. In vitro evaluation of ibuprofen-loaded microspheres prepared from novel chitosan/poly(vinyl alcohol) interpenetrating polymer network. Polym Plast Technol Eng 2014;53:371-8.

68. Fernandez Carballido A, Herrero Vanrell R, Molina Martinez IT, Pastoriza P. Sterilized ibuprofen-loaded poly(d,l-lactidecoglycolide) microspheres for intra-articular administration: effect of $\gamma$-irradiation and storage. J Microencapsul 2004;21:653-65.

69. Ramteke KH, Jadhav VB, Kulkarni NS, Kharat AR, Diwate SB. Preparation, evaluation and optimization of multiparticulate system of mebendazole for colon targeted drug delivery by using natural polysaccharides. Adv Pharm Bull 2015;5:361-71.

70. Jain SK, Shukla M, Shrivastava V. Development and in vitro evaluation of ibuprofen mouth dissolving tablets using solid dispersion technique. Chem Pharm Bull 2010;58:1037-42.

71. Swamy BY, Yun Y. In vitro release of metformin from iron (iii) cross-linked alginate-carboxymethyl cellulose hydrogel beads. Int J Biol Macromol 2015;77:114-9.

72. Patel N, Lalwani D, Gollmer S, Injeti E, Sari Y, Nesamony I. Development and evaluation of a calcium alginate based oral ceftriaxone sodium formulation. Prog Biomater 2016;5:117-33.

73. Lim V, Peh KK, Sahudin S. Synthesis, characterisation, and evaluation of a cross-linked disulphide amide-anhydridecontaining polymer based on cysteine for colonic drug delivery. Int J Mol Sci 2013;14:24670-91.

74. Gamcsik MP, Kasibhatla MS, Teeter SD, Colvin OM. Glutathione levels in human tumors. Biomarkers 2012;17:671-91.

75. Lau YK, Lim V. Colon targeted drug delivery of branch-chained disulphide cross-linked polymers: design, synthesis and characterisation studies. Chem Cent J 2016;10:1-19.

76. Holowka EP, Bhatia SK. Drug delivery: materials design and clinical perspective. New York: Springer; 2014. 